This is the peer reviewed version of the following article: Árnadóttir, S. T. (2013), Bodily Thought and the Corpse Problem. European Journal of Philosophy, 21: 575-592. doi: 10.1111/j.1468-

0378.2011.00463.x, which has been published in final form at

http://onlinelibrary.wiley.com/doi/10.1111/j.1468-0378.2011.00463.x/full. This article may be used for non-commercial purposes in accordance With Wiley Terms and Conditions for self-archiving. 


\title{
Bodily Thought and the Corpse Problem
}

\author{
Steinvör Thöll Árnadóttir
}

\begin{abstract}
A key consideration in favour of animalism - the thesis that persons like you and me are identical to the animals we walk around with-is that it avoids a too many thinkers problem that arises for non-animalist positions. The problem is that it seems that any person-constituting animal would itself be able to think, but if wherever there is a thinking person there is a thinking animal distinct from it then there are at least two thinkers wherever there is a thinking person. Most find this result unacceptable, and some think it provides an excellent reason for accepting animalism. It has been argued, however, that animalists face an analogous problem of too many thinkers, the so-called corpse problem, as they must accept both i) that we are distinct from our bodies, as our bodies can and we cannot persist through death as corpses and ii) that our bodies can think. I argue that the best reasons animalists have for accepting the two claims that generate the distinctness part of the problem double up as reasons to reject the claim that our bodies can think, and vice versa. I argue further that Lockeans cannot similarly get around their problem of too many thinkers.
\end{abstract}

1.

Central to the current debate on personal identity is the opposition between animalism and Lockeanism. The core claim of animalism is that persons are identical to the human animals they walk around with. The core claim of Lockean accounts is that persons have psychological persistence conditions, such that psychological continuity of some relevant kind is both necessary and sufficient for their persistence. Both claims look initially plausible but they are incompatible, as no kind of psychological continuity is necessary for the persistence of animals. This is shown, for instance, by the fact that animals start out as early term fetuses and can survive in persistent vegetative state. As neither early term fetuses nor human beings in persistent vegetative state have any psychological properties, no kind of psychological continuity can be necessary for the persistence of a thing that was once a person and could end up in persistent vegetative state. Thus, animalists are committed to denying that we have psychological persistence conditions and Lockeans are committed to denying our animal identity. The question is which one of these initially plausible positions we ought to favour.

\subsection{The Problems of the Thinking Animal}

Perhaps the strongest (though by no means the only) argument in favour of animalism and against the predominant Lockean accounts is that denial of our animal identity brings with it a vexing problem of too many thinkers (see e.g. Olson 1997, 1997a, 2003; Snowdon 1990; and Mackie 
1999). Those who deny our animal identity typically hold that we are constituted by animals in something like the way statues are thought to be constituted by lumps. ${ }^{1}$ But animals that constitute persons would appear to share with the persons they constitute all the properties relevant to having thoughts. To name but a few, they have the same brains, the same nervous systems, the same sensory systems, the same environmental inputs and the same behavioural outputs. Last, but by no means least, they are precisely the right sort of things to be the subjects of thought. Given this, it looks exceedingly plausible that any animal that constitutes a thinking person is itself a thinking thing. But when you combine the claim that person-constituting animals can think with the claim that persons are distinct from their constituting animals, troubles arise. For if any animal that constitutes a thinking person is itself a thinker, and any animal is numerically distinct from the person it constitutes, then we get the rather unappealing result that there are at least two thinkers wherever there is a thinking person. And the point generalizes not just across thinkers, but also across other mental states. Thus, whenever a person thinks a thought, has a pain, sees red, experiences a pang of desire, etc., the animal that constitutes it does too.

This inflation in number of thinkers strikes many as unacceptable in itself, but it also breeds further problems. One problem is that the referent of ' $\mathrm{I}$ ' is usually taken to be the thinker or speaker of the thought or utterance, but if the animal and person are distinct, and both have the capacity for thought, then we get a competition for the reference of 'I', resulting in a number of problems to do with meaning, truth, and the individuation of thoughts (see e.g. Noonan 1998, 2001; Mackie 1999; and Olson 2002a). Another problem is that the excess of thinkers lands us in a precarious epistemological situation. My animal and I would seem to have the very same justification for thinking we are (identical to) a person and thinking that we are (identical to) an animal. Supposedly, however, only one of us is right in each case. Worse, it seems that we could never know which one we are (see Olson 1997a, 2002). A third problem is that if personconstituting animals share the mental life of the persons they constitute, we are faced with the following dilemma: Either we must accept that there are two persons wherever there is one, or we must abandon a very natural understanding of personhood, - one that concurs roughly with Locke's characterization of a person as 'a thinking intelligent being that has reason and reflection and can consider itself as itself, the same thinking thing in different times and places' (Locke 1975: II. xxvii. 
9). (For this point see Snowdon 1990). ${ }^{2}$ We can refer to these problems collectively as the problems of the thinking animal. For the present purposes, there is no need for detailed discussion of them. We need only note that it is widely accepted that they are genuine problems that any satisfactory account must either avoid or solve.

Clearly, if persons are identical to the animals they walk around with, then the problems of the thinking animal will not arise. For if persons are identical to their animals, then there is no excess of thinkers to create the problems. Or at least there is not an excess of thinkers arising from the non-identity of persons with their animals. And this can be seen to be a very strong argument in favour of animalism, particularly in the absence of a satisfactory Lockean solution. ${ }^{3}$

\subsection{The Corpse Problem}

Lockeans have retorted, however, that animalists face their own problem of too many thinkersthe so-called 'corpse problem'-arising from their having to affirm both that we are distinct from our bodies and that our bodies can think (see e.g. Shoemaker 1999, 1999a, 2008; Baker 2000). As we have just seen the claim that our animals can think plays a crucial role in a key argument for animalism. But, it is claimed, if the animalist is right that our animals can think, then we must also accept that our bodies can think. For, given that they share with them all matter and microphysical properties, they should also share with persons the relevant properties for having thoughts. Commitment to our distinctness from our bodies, on the other hand, is meant to follow from consideration of ordinary cases of death -hence 'the corpse problem'. Commonsense, it is pointed out, tells us quite plainly that our bodies do not (normally) go out of existence at death but rather continue to exist as corpses. There are exceptions to this, of course, in cases of particularly violent deaths (by explosion or fire, say) but most of the time we're happy to say that our bodies continue to exist as corpses when we die. Indeed, most people would probably agree with Shoemaker that it is 'overwhelmingly natural to say that what after death is a person's corpse is something that existed, as that person's body, prior to death—that scars and tattoos on its surface are traces of things that happened to it earlier' (1999a: 499). ${ }^{4}$ On the other hand, most philosophers, animalists included, would deny that we ourselves can persist through death as corpses. Indeed, that we go out of existence at death is widely regarded a commonsense truth on par with the truth that our 
bodies do not. But, if we cannot persist through death as corpses and our bodies can, then it follows straightforwardly that we are not identical to our bodies.

If animalists must accept both that we are distinct from our bodies and that our bodies can think, they face an exactly similar problem to the one that they claim shows non-animalist positions to be untenable. Because if any body that constitutes a thinking animal is itself a thinker and any body is numerically distinct from the thinking animal it constitutes, then there are at least two thinkers wherever there is a thinking animal. And once this excess of thinkers is in place, further problems to do with reference and knowledge will again follow. The intended moral is that nothing would be gained by adopting animalism; we would merely replace the problems of the thinking animal with problems of the thinking body. Moreover, it has been thought that if animalists have a solution to the problems of the thinking body, then Lockeans should have a similar solution to the problems of the thinking animal. It is important, then, for animalists to show that they are not committed to the claims that generate the corpse problem and to show that their solutions do not generalize to the Lockean problems. This paper is aimed at doing precisely that.

\subsection{Responding to the Corpse Problem}

As we have seen, the corpse problem is generated by three claims: 1) that we cannot persist through death as corpses, 2) that our bodies can persist through death as corpses, and 3) that our bodies can think. The first two claims jointly entail that we are distinct from our bodies and the third claim makes this distinctness problematic by attributing thought to our bodies. In order for the corpse problem to threaten animalists, they must be committed to all three claims. But, I shall argue, they are not. First, it should be noted that if animalists are committed to these claims it is not by virtue of their being animalists. The thesis that we are identical to animals entails that we have the persistence conditions of animals; but it entails nothing about what the persistence conditions of animals are, even less about the persistence conditions or mental capacities of bodies. Given this, acceptance of the three claims is not, as it were, built into the animalist position. ${ }^{5}$ Of course, there might nonetheless be good reasons why we ought to accept these claims. Indeed, each claim has something to be said in its favour. I want to argue, however, that while on preliminary inspection each individual claim may look quite plausible, on closer inspection it is difficult to see how all three 
claims could be true at once. The best reasons we have for jointly accepting the claims that generate our distinctness from our bodies undermine the claim that our bodies can think, and vice versa.

I will proceed as follows. In section two, I shall briefly discuss the claim that our bodies can think and argue that the clearest reasons one might have for accepting it double up as reasons to doubt that the two claims that generate the distinctness part of the problem can be jointly true. In section three, I shall approach things from the other end and argue that the best reasons we have for accepting both that we cannot persist through death as corpses and that our bodies can double up as reasons for denying that our bodies can think. In section four, I will argue that the considerations offered in this paper do not generalize to the problems of the thinking animal. ${ }^{6}$

\section{2.}

Unlike the other two claims of the corpse problem, the claim that our bodies can think does not derive its support from commonsense. It is deeply counterintuitive to say that our bodies can think, or indeed that our bodies perform any of the actions (mental or otherwise) that we ordinarily attribute to persons. David Wiggins goes so far as claiming that ' $[\mathrm{t}]$ here is something absurd—so unnatural that the upshot is simply falsity —in the proposition that people's bodies play chess, talk sense, know arithmetic, or even play games or sit down' (1967: 152). While I do not think that the absurdity of the claim that our bodies can think strictly implies its falsity (see 2.1. below), I think it does show that one would have to have good theoretical reasons to accept it. What I want to suggest here, however, is that the theoretical reasons that would most obviously commit us to accepting the claim that our bodies can think ought also make us doubt that the first two claims of the corpse problem can both be true.

\subsection{Bodily Thought and Bodily Identity}

There is a way, though not perhaps a very natural way, of understanding the word 'body' in such a way that you just are your body. Indeed, this is the way that some animalists have wanted to understand the term. And clearly, if you had an argument for our identity with our bodies, that would double up as an argument for the claim that our bodies can think. For if you can think, and 
your body is identical to you, then it follows straightforwardly that your body can think. More generally, if your body is identical to you, and you play chess, talk sense, and know arithmetic, then it is true to say that your body plays chess, talks sense, and knows arithmetic, no matter how unnatural it may seem. ${ }^{7}$ Leaving aside whether this is a good view to hold, it is one that would give us bodily thought. But of course such a view would face no corpse problem. For plainly, if we were identical to our bodies, no two claims that entailed our distinctness could be jointly true. To get the corpse problem off the ground we need not only a reason to think that our bodies are capable of thought. We need a reason to think that our bodies are capable of thought that does not presuppose that our bodies are identical to us.

\subsection{A Physicalist Commitment?}

It is sometimes assumed that animalists have a particular physicalist commitment to bodily thought, arising from the arguments they must give in support of their position. The idea is that in order to argue that our animals can think, animalists must rely on a principle to the effect that objects that share all their matter and microphysical properties must share all their mental properties. And, further, that in adopting such a principle animalists commit themselves not only to thinking animals but also to thinking bodies. This idea is contained, for instance, in the following passage from Shoemaker:

\footnotetext{
If physical properties determine mental properties, then there is the same case for saying that this bodily entity shares the mental properties of the animal ... as there is for saying that ... the human animal shares its mental properties with the person. And, of course, if we can find a plausible way of denying that the bodily entity (the corpse-to-be) shares the mental properties of the person, this may provide us with a way of denying that the human animal shares the mental properties of the person (Shoemaker 1999a: 499). ${ }^{8}$
}

It is obviously true that anyone who holds such a principle has to agree that our bodies can think. However, animalists are no more committed to this principle than non-animalists are and although they might appeal to this principle to argue that our animals can think they need not do so. Although this is not often enough appreciated, the reason for believing that person-constituting animals can think lies not solely in that they are composed from the same matter and have the same microphysical properties as the persons they constitute, but also in the sort of things they are. While the claim that bodies can think is on its face preposterous, the claim that animals can think is really 
rather appealing. Animals are living things that interact with their environment and act purposefully in their strive to stay alive. Consciousness, perception, and eventually higher order thoughts have evolved due to their effectiveness in aiding their survival. It is hard to think of things better suited to being the subjects of thought. So even if we allowed that coincident things can differ in their properties, there would still be pressure on the Lockean to accept that animals can think. In any case, insofar as the aim is to demonstrate that animalists have a corpse problem, it is not effective to appeal to their alleged commitment to this physicalist principle. For animalists who did accept the principle will most likely do so for the reason that they accept a more general principle to the effect that coincident objects must share all their properties. And that principle is incompatible with the claim that we have different persistence conditions from our bodies, and indeed with any property difference claim that might be given as evidence for our distinctness from our bodies.

\subsection{Summary}

I do not pretend to have shown that there is no theoretical space to hold at the same time that our bodies can think and that we are distinct from our bodies. But it is not clear what the motivation for such a view could be. Given the apparent absurdity of the claim that our bodies can think we would need some strong theoretical considerations to accept it. But the theoretical considerations that would most obviously commit us to it would simultaneously undermine the distinctness claim.

\section{3.}

I turn now to arguing that the best reasons we have for accepting jointly that we cannot persist through death as corpses and that our bodies can double up as reasons for denying that our bodies can think. I will structure my discussion around the claim that we cannot persist through death, and I will follow Feldman (1992) in calling this the termination thesis. I will isolate the best reasons we have for accepting this thesis, and then look at what sort of things our bodies would have to be for the same reasons not to be applicable to them. The intended moral will be that insofar as we have reason to accept both that we terminate at death and that our bodies do not, then we also have reason to think that our bodies are not the sort of things that can think. 


\subsection{The Termination Thesis and Commonsense}

Judging from my interactions with other philosophers I would guess that most of them accept the termination thesis, and that many take it to have the status of a commonsense truth. Indeed, I have even heard it suggested that it is analytic that we could not persist through death as corpses. ${ }^{9}$ This is not, however, obviously borne out by our ordinary linguistic practices and judgments. As opponents of the termination thesis have been keen to point out, we are in general perfectly happy to speak of 'dead people'. Judith Jarvis Thomson (1997: 202), for instance, claims that it is just obvious that if a house full of people collapsed its ruins would contain dead people, and Fred Feldman (1992: 104) makes a similar point about natural disasters leaving dead people in their wake. We also debate whether we would rather be cremated or buried, and when our loved ones die we take measures to bury them. Indeed, we place gravestones on people's graves that bear inscriptions such as 'here lies...' followed by people's names or phrases such as 'my dearly beloved mother'. Feldman claims that in many cases these inscriptions are literally true, and that ' $[\mathrm{t}] \mathrm{he}$ fact that so many of these inscriptions seem plausible demonstrates the pervasiveness of the idea that people do not go out of existence when they die' (2000: 102).

Insofar as they are intended to refute the termination thesis, these considerations are rather less than conclusive. If people are willing to say that the previously living person is lying in her coffin, they are equally willing to say that she is 'gone', and that the thing in the coffin is 'not really her', but 'only her body'. Indeed, such talk is very common, and this is why the termination thesis looks at least initially appealing. What I think these considerations do show, however, is that the termination thesis is at least not an analytic truth, and that our commonsense judgments and linguistic practices do not obviously commit us to it. Ordinary talk is, to say the least, hazy on the metaphysics of persistence. Thus, if we are to accept the termination thesis we need to be given some good reason for doing so. In (3.3) below I will consider what I take to be the strongest reason an animalist might have for accepting the termination thesis. But I will start with two potential reasons that will not do. 


\subsection{Two Reasons That Ought Not Persuade the Animalist of the Termination Thesis}

You might be drawn to the termination thesis on basis of the following line of thought: 'We are talking about personal identity here and anything that is to count as identical to a person must itself be a person. In order to be a person, however, a thing must be appropriately psychologically endowed, and a 'dead person' is not psychologically endowed at all. So a dead person is not strictly speaking a person and cannot be identical to a person.' If such considerations seem initially persuasive, however, they should not impress the animalist. Animalists are anyway committed to the claim that we may persist through the loss of all our mental properties and survive as non-persons (in this psychological sense of 'person'), for instance by going into persistent vegetative state. Thus, animalists reject the claim that anything that is to count as identical to a person must itself be a person. They hold that the claim that a person at one time may be identical to a non-person at another time is on par with the claim that a child at one time can be identical to a non-child at another time. ${ }^{10}$ Adult children are not children, for instance, but a woman's adult children are still her children in the sense that they are the very same individuals as her children. Similarly, an animalist could claim that although a dead person is not a person, it is nonetheless the same individual as the once living person.

Now, as it happens, although all animalists should happily allow that persons can persist as non-persons, most animalists would deny that animals can persist as non-animals. For most animalists, proponents and opponents of the termination thesis alike, believe that any animal is essentially an animal in the sense that it could not cease to be an animal without ceasing to exist. ${ }^{11}$ Thus, although no animalist should accept the termination thesis on the grounds that a dead person is not a person, some animalists might accept the termination thesis on the grounds that a dead animal is not an animal. As it stands, however, this is not a compelling reason. For it is not clear that we should accept that dead animals are not animals. What's more, it is really not clear how one might argue that a dead animal is not an animal independently of arguing for the termination thesis.

One might perhaps appeal to dictionary entries to argue that it is part of our concept of an animal that an animal is a living thing, much like it is part of our concept of a person that a person is a psychologically endowed thing. ${ }^{12}$ But whatever support one might have from such appeals is countered by evidence that suggests we are perfectly happy to take the carcasses of animals to be the very things that used to be living things. For instance, Feldman (1992) gives a nice example of a 
butterfly collector who goes out and catches butterflies in the morning and then mounts them on a board with pins in the evening. It would be absurd, he claims, to deny that the things that the man pins onto the board in the evening are the butterflies that he caught in the morning. There is something rather appealing about this. And while such considerations provide no knockdown argument against the claim that dead animals are not animals, I think they do show that we cannot argue for the termination thesis simply by appealing to the claim that a dead animal is not an animal. Rather, we need some argument to persuade us of both claims at once. That is to say, we need some argument to persuade us both that we necessarily go out of existence at death and that a dead animal is not an animal. I turn now to what seems to me the argument most likely to do this.

\subsection{On the Fundamental Differences Between the Living and the Dead}

You might hold that we cease to exist at death not because we are animals and animals are by definition living things, but rather because animals are living things and anything that is a living thing is necessarily a living thing. This claim is not to be confused with the claim that necessarily anything that is a living thing is a living thing, which is quite trivial and uninteresting. Rather the idea is that there is something so special and distinctive that living things have by virtue of living that they could not possibly cease to live without ceasing to exist altogether. This thought goes all the way back to Aristotle and continues to persuade some theorists today.

A natural way to motivate the claim that living things are essentially living things is to appeal to the drastic differences that hold between living and dead things. One such argument is given by Olson (2004). Things, Olson holds, have certain principles of persistence that determine how they can and do continue to exist. And, he argues, the principles of persistence of living things such as ourselves are so drastically different to those of corpses that we could not be the same things. Corpses are not responsive to their environment in the autonomous way that we are, and they do not engage in the same level of self-perpetuation and self-maintenance. There is no storm of life organizing their activities, only the lull of death. A corpse will not grow new skin where you scratch it, digest the food that you place inside it, or fight the parasites eating its flesh. It lacks most of our functions, and its means of persisting are more akin to those of a marble statue (or better, perhaps, a hunk of meat) than to those of a living human being. 
A corpse, like a marble statue, maintains its form merely by virtue of the intrinsic stability of its materials. The stability of a living thing, by contrast, is dynamic. A living thing maintains its form-in particular the fine biochemical structure that makes it alive-only by engaging in constant activity: repairing damage, removing waste, fighting infection, acquiring and digesting food, and so on. All of this comes to an end when the organism dies. Matter ceases to flow. The repairs stop. Decay sets in. (Olson 2004: 269).

Thus, holds Olson, despite the surface similarities, a corpse is really a fundamentally different sort of thing from the living animal, with fundamentally different principles of persistence, and could not be identical to it.

I think that any animalist who accepts the termination thesis will very likely be motivated by some version of this argument. More, if we assume that such considerations ought to persuade us that we cannot persist through death as corpses, the corpse problem starts to rear its head. ${ }^{13}$ But the animalist who is persuaded by these considerations is not yet in trouble. For in order for the corpse problem to arise, the animalist needs to be obliged to accept not just that we cannot persist as corpses, but at the same time that our bodies can. And then we must ask: how could the considerations that apply to us fail to apply to our bodies? If our bodies had all the features that supposedly make us fundamentally different from and so distinct from corpses, then precisely the same arguments ought to apply to them as apply to us, and they too would be fundamentally different and distinct from corpses. ${ }^{14}$ So if we cannot persist through death as corpses because we are living things (and/or because we have the various functions that go with being living things), then if our bodies can persist through death as corpses they must not be living things! Once this is noted, the corpse problem starts to unravel.

\subsection{Unraveling the Corpse Problem}

The claim that the bodies of living persons are not themselves living things ought to strike a familiar cord from the metaphysics of material objects more generally. It is, for instance, akin to the claim that lumps of clay constitute things that are (essentially) statues but are not themselves (essentially) statues, and that is a thesis so widely accepted that it has been described as 'the standard account' of the relationship between statues and lumps. If that's the standard account, however, there is also a standard objection to it. Given that coincident objects (statues and lumps, bodies and persons, etc.) are composed of exactly the same matter, arranged in the same way, under 
the same circumstances, the objection runs, there could not be anything that explains or 'grounds' the alleged difference in properties between them. So we cannot truly attribute different properties to coincident objects. This is known as the grounding problem. The grounding problem has generated a sizeable debate, the resolution of which turns on large metaphysical questions, and I cannot enter into this debate here. ${ }^{15}$ But we do not need to establish whether or not we can coherently deny that our bodies are living things. The corpse problem is undermined either way.

Assume first that we cannot in fact coherently deny that the bodies of living things are themselves living things. Then we face a choice. On the one hand, we could accept the second claim of the corpse problem, that bodies can persist through death as corpses. This would, however, seriously undermine the first claim, that we necessarily go out of existence at death. For the best reason we had for accepting this was precisely that living things are so different from dead things that nothing could be first alive and then dead. And if our bodies are living things that can persist through death as corpses, then there are some things that are first alive and then dead. On the other hand, we could accept that no living thing ever persists as a dead thing, and so accept that we cannot persist through death as corpses. But then we must also deny that our bodies can persist through death as corpses. Either way, there is no corpse problem.

Now assume instead that we can coherently deny that the bodies of living things are themselves living things; that bodies constitute living things but are not strictly speaking themselves living things. That would allow us to simultaneously accept the first and second claims of the corpse problem. However, it would also seriously undermine the third claim employed to generate the corpse problem, that our bodies can think. For if our bodies are mere receptacles in which life occurs, if they give rise to life but are not themselves the right sort of things to be the subjects of this life, then surely we should also say that they are mere receptacles in which thought occurs and that they (or some parts of them perhaps) give rise to thought but are not themselves the right sort of things to be the subjects of thought. And then, again, there is no corpse problem.

\subsection{Summary}

I have argued that the best reasons we have for accepting both of the claims that generate the distinctness claim of the corpse problem double up as reasons to reject the thought claim. I cannot, 
of course, rule out that there are some other reasons for why we ought simultaneously to accept both the first and the second claim of the corpse problem that do not undermine the claim that our bodies can think. But if there are such reasons we need to be told what they are and why we ought to be persuaded by them. Meanwhile, it seems fair to say that the corpse problem presents no serious threat to the animalist.

4.

I said above that I wanted to show both that animalists have a solution to the corpse problem, and that their solution does not generalize the Lockean problem of too many thinkers. I hope that the above considerations have achieved the first of these tasks. I want to conclude the paper by undertaking the second task.

I argued for two main claims above, the first of which was that the considerations that might persuade animalists that bodies can think ought also to persuade them that the two claims that generate the distinctness part of the corpse problem cannot both be true. I shall not here discuss the analogous move for Lockeans. I.e. I shall not here discuss whether the considerations that might persuade us that animals can think ought also to persuade us that the two claims that generate the distinctness part of the problems of the thinking animals cannot both be true. I note only that if they did that would be an unwelcome consequence for Lockeanism. This is because the distinctness part of the Lockean problem is generated by two claims neither of which Lockeans can reasonably reject. Namely, that psychological continuity is necessary for our persistence and that psychological continuity is not necessary for the persistence of animals. Rejecting the first of these claims is not an option for Lockeans as it would in effect amount to giving up Lockeanism. Rejecting the second claim, on the other hand, while consistent with Lockeanism, is quite hopeless on other grounds. ${ }^{16}$

The second claim I argued for was that the reasons that might sway the animalist to accept both that we cannot survive death as corpses and our bodies can, ought also lead them to deny that our bodies can think. The next three sections will be concerned with a possible parallel with this second claim. More specifically, they will be concerned with showing that it is not the case that the 
arguments that sway the Lockean to accept both that we cannot survive mental death as human vegetables and animals can ought also lead them to believe that animals cannot think.

\section{1.}

Many (perhaps most) psychological continuity theorists are motivated by two distinct ideas that they derive from Locke. The first is Locke's famous definition of a person as 'a thinking intelligent Being, that has reason and reflection, and can consider itself as itself, the same thinking thing in different times and places' (Locke 1975: II, XXVII, \9). The second idea is that there can be 'no personal identity without a person' (Baker 2000: 121). A person, the thought runs, is what we essentially or most fundamentally are, and so no person could have existed as a non-person or come to exist as a non-person. Taken together, these two ideas entail that persons cannot survive the loss of all their mental properties. What's more, given that animals are not essentially or most fundamentally persons, the same considerations fail to apply to them. So we have a potential explanation (or part explanation) for why animals can and persons cannot survive mental death that reflects the actual motivations of many Lockeans. This potential explanation, however, gives us no reason to doubt animal thought. If Lockeans are right that persons are essentially psychologically endowed then of course all persons must at all times have some mental properties. But this leaves open that other things have mental properties for only some of the time. So we cannot conclude merely from the fact that animals can survive the loss of all their mental properties that they never had any. We would need in addition an argument for why the bearers of mental properties should bear mental properties necessarily.

\section{2.}

Lynne Rudder Baker (2000) claims that what fundamentally distinguishes persons from nonpersons is the possession of a first-person perspective, 'a perspective from which one thinks of oneself as an individual facing a world, as a subject distinct from everything else' (Baker 2000: 60). This Baker claims, quite plausibly, is what enables us to engage in sophisticated communication with each other, and provides the very foundations of our civilization. It is also, she holds, what 
makes us fundamentally different from animals. Animals, Baker thinks, can have various lower order thoughts and a weak first-person perspective; 'a certain perspective on [their] surroundings with [themselves] as the "origin"” (Baker 2000: 61). But no animal has a strong first-person perspective. This, Baker claims, is of such fundamental importance that it requires its own special kind of thing to have it, different in kind from anything that does not have it:
Although I agree that human animals normally develop the capacity to support first-person perspectives, it seems obvious (to me, anyway) that anything capable of having a first-person perspective is basically different from anything incapable of having one. (Baker 2000: 16, my italics)

Moreover, Baker argues, human animals cannot be the bearers of the first-person perspective because they are not fundamentally different in kind from non-human animals that lack it. In support of this, she appeals to Darwin and tells us that 'Darwin's message is that human animals are not basically different from non-human animals' (Baker 2000: 16).

If Baker is right, then we necessarily go out of existence at mental death because mental death marks the end of our first-person perspective, and beings that are blessed with such a perspective are so drastically different from things lacking it that the two could not be identical. This would explain both why we cannot survive mental death (nor death insofar as this involves mental death) and why our animals cannot have a strong first-person perspective or the mental properties that go with that, being as they are capable of surviving mental death. ${ }^{17}$ All this rests, however, on the claim that beings with a first-person perspective are fundamentally different from beings that lack it, and Baker's argument for this claim are less than persuasive.

Baker is undoubtedly right that the first-person perspective is of extreme cultural and historical importance. Indeed, she may even be right that it is the distinguishing feature of persons and that which sets us apart from all non-human animals. But this is not yet reason to think that the first-person perspective is ontologically significant in the way she thinks it is. It is not yet reason, that is, to think that we must be fundamentally different kinds of beings from non-human animals (and a forteriori from human animals). The difference might be one of degree rather than kind. Moreover, Baker's own appeal to Darwin's findings, together with her account of what mental capacities animals do possess would seem to go rather better with the view that we are not 
fundamentally different kinds of beings from animals. Darwin showed us how species evolve to have progressively more complex and sophisticated functions that make them more adaptable to their environments. Thus, for instance (and by Baker's own admission) animals evolved to acquire consciousness, a weak first-person perspective and rudimentary beliefs and desires. But if lower order thought and weak first-person perspective do not require a special kind of thing to have it, it is difficult to see that there is any good reason to think that strong first-person perspective would.

\section{3.}

A more promising response, perhaps, would be to claim that anything that has any mental properties necessarily has mental properties. As before, this claim is not to be confused with the claim that necessarily anything that has mental properties has mental properties, which is trivial. Rather the thought would be that there is something so special and distinctive that mentally endowed things have by virtue of being mentally endowed that they could not possibly cease to have mental properties without ceasing to exist altogether.

If you could argue for this claim, then you would indeed have a solution to the Lockean problem of too many thinkers, analogous to the one I suggested above. For if in order to have mental properties a thing must be such as to necessarily have mental properties that would explain both why we, as bearers of mental properties, must go out of existence at mental death and why our animals, as potential survivers of mental death, could not have mental properties. There are problems with this solution, however. The first problem is that it is not clear that there is any persuasive argument available for the claim that in order to have mental properties a thing must be such as to necessarily have mental properties. ${ }^{18}$ The second problem is that if we were to accept the claim we would be landed with some rather unappealing consequences. Assuming that any animal could survive mental death, the view would commit you to claiming both that no animal has any mental properties and that any animal that displays behaviour worthy of mental attributions constitutes something distinct from itself. This entails that there are many more things than we thought there were. Wherever we thought there was just a dog, for instance, we now must say that there is a dog and a conscious subject constituted by the dog. And even those who are not in principle opposed to coincident objects are liable to find this consequence unattractive. The 
multiplication, it seems, is simply not required, as we already have the right sort of thing in place to be the subject of consciousness - an animal.

Finally, it seems rather unhappy to separate the subjects of sentience and thought from the subjects of life. Consciousness evolved due to its effectiveness in securing and prolonging life. Indeed, we might think of consciousness as a form of responsiveness to the world aimed at prolonging life. And certain mental properties, such as pain, fear and anxiety, seem interwoven with various life functions. So, it seems natural to think that these properties are borne by the same subjects. More generally, it seem natural to assume that the properties that evolved because of their effectiveness in aiding the survival of animals are had by animals themselves, rather than by things distinct from them.

5.

It has been the aim of this paper to show both that animalists are not committed to the claims that generate the corpse problem and that their solutions do not generalize to the Lockean problem. The corpse problem is generated by three claims: that we cannot persist through death as corpses, that our bodies can persist through death as corpses, and that our bodies can think. But not only are none of these three claims entailed by animalism, it is hard to see how an animalist could be committed to all three claims at once. I have argued that the best reasons for accepting the first two claims suggest that the third claim is false and that the best reasons for accepting the third claim suggest that the first two claims cannot both be true. Given this, the corpse problem does not so much as get off the ground. I have argued further that analogous solutions do not lend themselves to the Lockean problem. At least as far as too many thinkers are concerned, animalists are in a considerably stronger position than Lockeans. ${ }^{19}$

Steinvör Thöll Árnadóttir Faculty of Philosophy University of Cambridge sta29@cam.ac.uk 


\section{References:}

Árnadóttiir, S. T. (2010), 'Functionalism and Thinking Animals', Philosopbical Studies, 147: 347-354.

Baker, L.R. (2000), Persons and Bodies: A Constitution View. Cambridge: Cambridge University Press.

Bennett, K. (2004), 'Spatio-Temporal Coincidence and the Grounding Problem', Pbilosopbical Studies, 118: 339371.

Burke, M. (1992), 'Copper Statues and Pieces of Copper: A Challenge to the Standard Account', Analysis 52: $12-17$.

Burke, M. (1997), 'Persons and Bodies: How to Avoid the New Dualism', American Pbilosophical Quarterly, 34: 457-467.

Carter, W. (1999), 'Will I be a Dead Person?', Philosophy and Phenomenological Research, 54: 161-171.

Feldman, F. (1992), Confrontations with the Reaper. Oxford: Oxford University Press.

Feldman, F. (2000), 'The Termination Thesis', Midwest Studies in Pbilosophy: Life and Deatb: Metaphysics and Ethics, 24: 98-115.

Fine, K. (2003), 'On the Non-Identity of a Material Thing and Its Matter', Mind, 112: 195-234

Locke, J. (1975), An Essay Concerning Human Understanding, P. Nidditch (ed.). Oxford: Clarendon Press. (First published 1694).

Lucci, (2006), State of Wisconsin, Circuit Court, Douglas County, Memorandum, dated Now 22, 2006. Case No. 06-CM-504. URL: http://www.thesmokinggun.com/archive/1122061deer1.html

Mackie, D. (1999), 'Animalism versus Lockeanism: No Contest', Philosophical Quarterly, 49: 369-376.

Mackie, D. (1999a), 'Personal Identity and Dead People', Philosopbical Studies, 95: 219-242.

Noonan, H.W. (1998), 'Animalism versus Lockeanism: A Current Controversy', The Philosopbical Quarterly, 48: 302-318.

Noonan, H.W. (2001), 'Animalism Versus Lockeanism: Reply to Mackie', The Pbilosopbical Quarterly, 51: 83-90.

Olson, E. (1997), The Human Animal: Personal Identity Without Psychology. Oxford: Oxford University Press.

Olson, E. (1997a), 'Was I Ever a Fetus?', Philosophy and Phenomenological Research, 57: 95-110

Olson, E. (2001), 'Review of L.R. Baker Persons and Bodies', Mind, 110: 427-430.

Olson, E. (2001a), 'Material Coincidence and the Indiscernibility Problem', The Pbilosophical Quarterly, 51: 337355.

Olson, E. (2002), 'What does Functionalism tell us about Personal Identity', Nous, 36: 682-698.

Olson, E. (2002a), 'Thinking Animals and the Reference of "I"', Pbilosopbical Topics, 30: 189-208.

Olson, E. (2003), ‘An Argument for Animalism', in R. Martin and J. Barresi (eds.) Personal Identity. Oxford: Blackwell.

Olson, E. (2004), 'Animalism and the Corpse Problem', Australasian Journal of Pbilosophy, 82: 265-274.

Olson, E. (2006), 'Is there a Bodily Criterion of Personal Identity?', in F. MacBride (ed.) Identity and Modality. Oxford: Clarendon Press.

Rosenberg, J.F. (1998), Tbinking Clearly About Death (2 ${ }^{\text {nd }}$ ed). Indianapolis: Hackett Publishing.

Shoemaker, S. (1999), 'Self, Body, and Coincidence', Proceedings of the Aristotelian Society Supp.Vol., 73: 287-306.

Shoemaker, S. (1999a), 'Eric Olson: The Human Animal', Nous, 33: 496-504.

Shoemaker, S. (2004), 'Functionalism and Personal Identity - A Reply', Nous, 38: 525-533.

Shoemaker, S. (2008), 'Persons, Animals and Identity', Synthese, 162: 313-324

Snowdon, P. (1990), 'Persons, Animals, and Ourselves', in C. Gill (ed.) The Person and the Human Mind. Oxford: Clarendon Press: 83-107. Reprinted in T. Crane and K. Farkas (eds.) Metaphysics: A Guide and Anthology. Oxford: Oxford University Press 2004: 578-596.

Thomson (1997), 'People and Their Bodies', in J. Dancy (ed.) Reading Parfit. Oxford: Blackwell.

van Inwagen, P. (1980), 'Philosophers and the words "human body”, in P. van Inwagen (ed.) Time and Cause. Dordrecht: Reidel.

Wasserman, R. (2002), 'The Standard Objection to the Standard Account', Philosophical Studies, 111: 197-216.

Wasserman, R. (2004), 'The Constitution Question', Noûs, 38: 693-710.

Wiggins, D. (1967), Identity and Spatio-Temporal Continuity. Oxford: Basil Blackwell.

Wiggins, D. (1968), 'On being in the Same Place at the Same Time', The Pbilosophical Review, 77: 90-95. 


\section{Notes:}

${ }^{1}$ How exactly constitution ought to be understood is a matter of debate (for an overview, see Wasserman 2004). But constitution is normally taken to involve at least the sharing of all matter (or all parts at some level of decomposition) and all microphysical properties. It is, as we might put it, 'as close to identity as a relation can get without being identity' (Baker 2000: 58).

${ }^{2}$ For discussion of the difficulty with giving a plausible characterisation of personhood that precludes the animal from being a person see Snowdon (1990) and Olson (2002a). Embracing the other horn of the dilemma has metaphysical implications concerning coincidence and sortal properties that we cannot go into here.

3 Although I cannot argue for this claim here, I believe that Lockeans have thus far failed to give satisfactory solutions to the problems of the thinking animal, and I doubt very much that any such solution is forthcoming. Three main responses offered by Lockeans are those of Harold Noonan (1998, 2001), Sydney Shoemaker (1999, 2004, 2008), and Lynne Rudder Baker (2000). For arguments against Noonan see Mackie (1999) and Olson (2002a). For arguments against Shoemaker see Olson (2002) and Árnadóttir (2010). For arguments against Baker see Olson (2001).

${ }^{4}$ It should be noted, perhaps, that there are philosophers who profess not to understand what might possibly be meant by the words 'human body' and who doubt that there is any coherent notion of a human body (see Olson 2006, van Inwagen 1980, and Rosenberg 1998). As I do not myself feel the force of this worry, and as there isn't space to address it here, I mention it only to set it to one side.

5 Animalists have indeed rejected each of them. David Mackie (1999a), William Carter (1999) and Fred Feldman $(1992,2000)$ reject the first claim, that we cannot persist through death as corpses, and argue that each one of us can literally end up dead and buried. Eric Olson (2004) rejects the second claim, that our bodies can persist through death as corpses, and argues that there is no such thing as a body that is first alive and then dead. David Wiggins (e.g. 1967) - albeit not in response to the corpse problem - rejects the third claim, that our bodies can think.

${ }^{6} \mathrm{I}$ should stress that my primary aim is not to establish which of the claims of the corpse problem we ought to accept, but rather to show that it makes little sense for the animalist to accept all three of them at once. This is so, we might add, for reasons quite independent of their generating a too many thinkers problem.

${ }^{7}$ Of course, your body will not do any of these things because it is a body. But if your body is identical to you it is no mere body; it is a body that has all the life functions and cognitive activities of a fully functioning human animal.

8 It appears also in Burke (1997), Baker (2000), and Olson (2001).

${ }^{9}$ Baker (2000) comes close to defending this claim and Jay Rosenberg (1998) argues that the claim that we might persist through death is logically incoherent.

${ }^{10}$ One way to express this thought is that 'person' is a phase sortal, under which a thing may fall for only part of its existence, like 'child' or 'teenager'.

11 This thought is sometimes expressed by saying that 'animal' is a substance sortal, under which a thing must fall for the duration of its existence, if at all.

${ }^{12}$ Incidentally, the question of whether dead animals are animals was at the centre of a reasonably high profile court case in the state of Wisconsin not long ago, where such an appeal was made. A young man who was 
accused of violating a bestiality law prohibiting any person from committing 'an act of sexual gratification involving his or her sex organ and the sex organ, mouth or anus of an animal' (Lucci, 2006) filed for dismissal of the charges against him, on the basis that the 'animal' in question was dead and so not strictly speaking an animal. Here is the Judge's summary of the defendant's motion: 'The gravamen of the defendant's challenge is that since the complaint alleges that he had sex with a dead deer, he cannot be guilty of committing an act of sexual gratification with an animal in the context and within the meaning of sec. 944.17(2)(c) Wis. Stats. He contends that the statute does not prohibit one from having sex with a carcass since the usual or common definition of an animal in dictionaries refers to it as a "living being" or a "living individual", Webster's Dictionary defines it as "any of a kingdom of living beings". (Lucci 2006) Unfortunately for the defendant the judge rejected the motion on grounds that 'most people understand that an animal does not necessarily cease being or qualifying as an animal or even being referred to as an animal once it's dead' (Lucci 2006: 2). I do not know what evidence the judge had for this claim.

${ }_{13}$ We might add that unless we assume that these considerations ought to persuade us the corpse problem does not start to rear its head.

${ }^{14}$ Olson (2004) denies that our bodies persist through death on these grounds.

15 See e.g. Burke (1992) and Olson (2001a) for arguments based on grounding worries against distinct coincident objects. See e.g. Wiggins (1968), Fine (2003), Wasserman (2002) and Bennett (2004) for a defense of the idea that there can be distinct coincident objects that differ in their properties. Incidentally, wariness of coincident objects is for both Burke and Olson a key motivation for affirming our identity with animals, and no doubt others are similarly inclined. But there is not, as far as I can see, any principled reason why an animalist (by virtue of being animalists) ought not to allow that there are coincident objects.

${ }^{16}$ The claim that animals do have psychological persistence conditions entails, for example, that when a young human animal comes to have (or support) complex enough psychological features a new animal with psychological persistence conditions comes into existence. And it entails also that were this new animal to suffer a mentation-destroying blow to the head it would go out of existence. Further, in order to avoid there being two animals in the same place at the same time, the account would have to hold that the young human animal goes out of existence when the new thinking animal comes into being and that a brand new animal comes into existence when the thinking animal gets knocked into persistent vegetative state. Although such an account has been defended (see Burke 1997) I take these consequences to make it untenable.

${ }^{17}$ This would not rule out that our animals have various lower order thoughts, of course, but we can leave that aside for the moment..

${ }^{18}$ I am not aware of any argument that attempts to show exactly this. Shoemaker $(1999,2004,2008)$ argues that person-constituting animals cannot share the mental properties of the persons they constitute, as they do not have psychological persistence conditions, but I do not think his argument can aspire to establish the stronger claim that anything that has mental properties must necessarily have mental properties. In any case, I think the argument fails to establish its intended conclusion. For a discussion of Shoemaker's argument see Olson (2002) and Árnadóttir (2010).

${ }^{19}$ The final version of this paper was prepared while holding a Leverhulme Early Career fellowship. Thanks to Colin Johnston, Tim Crane, Eric Olson, Mark Eli Kalderon, Sonia Roca-Royes, Eyja Margrét Brynjarsdóttir, Keith Allen, and two anonymous referees for their comments on earlier versions. 